\title{
LINGUAGEM, AMBIENTE E COGNIÇÃO: A CAMINHO DE UMA PERSPECTIVA ECOLÓGICA DE CATEGORIZAÇÃO
}

\section{LANGUAGE, ENVIRONMENT AND COGNITION: THE WAY OF AN ECOLOGICAL PERSPECTIVE OF CATEGORIZATION}

\author{
Ilana Souto de Medeiros ${ }^{1}$ \\ Ricardo Yamashita Santos ${ }^{2}$ \\ Universidade Federal do Rio Grande do Norte
}

\begin{abstract}
RESUMO
Este artigo se propõe a apresentar, de modo breve, as características epistemológicas de dois conceitos fundamentais que constituem o arcabouço teórico da Linguística Cognitiva, a saber: cognição, situando-o desde a perspectiva clássica, especificamente no paradigma gerativista de Chomsky, até o modelo ecológico, considerado extensão da perspectiva corporificada, fundamentada por Lakoff e Johnson (1980); e categorização, abordando-o desde as discussões incitadas por Aristóteles, perpassando pelas propostas de Wittgenstein (1953), Eleanor Rosch e Mervis (1975) e Lakoff (1987) para, então, sugerir, a partir de uma visão geral da noção de frames trazida por Lakoff (2004) e Duque (2015a), ideias que possam nos levar a pensar em um paradigma ecológico de categorização. Espera-se, ao final, incitar discussões teóricas acerca dessa possível proposta.
\end{abstract}

PALAVRAS-CHAVE: Linguagem; cognição; categorização; ambiente.

\begin{abstract}
This paper proposes to describe briefly the epistemological features of two fundamental concepts that constitue the theorical framework of the Cognitive Linguistics. First, it will be addressed the cognition from the classical perspective, specifically focusing on the Chomsky's gerativist paradigma, to the ecologic model, considered the extension of the embodied perspective according Lakoff and Johnson (1980). Second, it will be the emphasized the categorization model, focusing on Aristotle's discussions, spanning trough Wittgenstein (1953), Rosch and Mervis (1975) and Lakoff's (1987) proposals. From this, we suggest ideas that might lead us to think of an ecological paradigma of categorization, according to Lakoff (2004) and Duque's (2015a) general overview of frame notion. Ultimately, we help to encourage theoretical disscusion on the above-mentioned proposal.
\end{abstract}

KEYWORDS: Language; cognition; categorization; environment.

\footnotetext{
1 Mestranda em Linguística Teórica e Descritiva pelo Programa de Pós-Graduação em Estudos da Linguagem da Universidade Federal do Rio Grande do Norte. E-mail: ilanasouto@hotmail.com

2 Doutor em Linguística Teórica e Descritiva pelo Programa de Pós-Graduação em Estudos da Linguagem da Universidade Federal do Rio Grande do Norte. E-mail: r.yamashita@unp.br
} 


\section{INTRODUÇÃO}

Se fizermos uma busca rápida em um dicionário de língua portuguesa, encontraremos diversas definições sobre linguagem, dentre as quais "faculdade que têm os homens de comunicar-se uns com os outros [...]", "maneira de falar, relativamente às expressões, ao estilo [...]", "modo de se exprimir por meio de símbolos, formas artísticas [...]"3, dentre outras.

Ao longo dos últimos séculos, a linguagem tem ocupado o centro de interesse das discussões em áreas como a filosofia, a psicologia, a linguística, dentre outras. Desde então, esforços foram depreendidos na tentativa de buscar respostas à questão "como produzimos linguagem?".

Durante a primeira metade do século XX, na linguística e em algumas outras ciências, de modo geral, tais respostas encontraram suporte na teoria comportamental de Skinner. Baseada na noção de uma relação mecânica entre estímulo e resposta, a linguagem passou a ser concebida como decorrente de fatores externos e mensuráveis.

A partir da década de 1950, sobretudo graças à consolidação das Ciências Cognitivas, a base behaviorista, que até então subsidiava as explicações de como produzimos linguagem, foi substituída. Nesse novo paradigma, fatores internos, até então desconsiderados, passaram a ocupar papel de destaque no modo pelo qual os fenômenos linguísticos eram compreendidos. Em outras palavras, surgiu o interesse em estudar a linguagem a partir de suas relações com a mente e seus respectivos processos.

Nesse cenário, que uniu linguagem e cognição, duas correntes distintas acerca dos estudos linguísticos ganharam forma: a da linguística cognitiva clássica, com o gerativismo de Chomsky, e a da linguística ecológica ${ }^{4}$, modelo mais atual que pode ser considerado uma extensão da abordagem corporificada, iniciada a partir dos estudos de Lakoff e Johnson (1980, [2002]).

Ao longo deste artigo, discorremos, a partir das perspectivas acima mencionadas, sobre dois conceitos fundamentais que fazem parte do arcabouço teórico da Linguística Cognitiva, a saber: cognição e categorização. Ao final, com base na noção de frames delineada por Lakoff (2004) e Duque (2015), propomos ser possível pensar em um novo modelo de categorização, intitulado, neste texto, de categorização ecológica.

\section{Cognição: da abordagem clássica à ecológica}

Como dito anteriormente, o surgimento das Ciências Cognitivas, na década de 1950, provocou uma ruptura com o modelo de análise dos fenômenos linguísticos que vigorou durante a primeira metade do século XX. Em outras palavras, a linguagem, que até então era analisada a partir de fatores externos, passou a considerar aspectos internos, como o funcionamento da mente.

A primeira corrente que se ocupou em estudar a descrição dos fatos linguísticos sob um viés cognitivo, o gerativismo de Chomsky, se insere no paradigma conhecido por Cognição Clássica. Neste, a linguagem é vista como um sistema autônomo, depositado no cérebro dos sujeitos e composto por princípios inatos referentes à estrutura gramatical das línguas (cf. CHOMSKY, 1957).

A mente, de acordo com a perspectiva gerativista, se configura como uma espécie de dispositivo biológico que atua independentemente de informações sensório-motoras. Ela é composta por módulos que atuam separadamente para desempenhar funções cognitivas

\footnotetext{
${ }^{3}$ Definições disponíveis em: <http://www.dicio.com.br/linguagem/>. Acesso em: 19 mar. 2016.

${ }^{4}$ Alguns estudos já abordam os fenômenos linguísticos pelo viés ecológico, como os de Couto (2009). Neste artigo, contudo, adotamos a noção ecológica a partir da perspectiva proposta por Duque (2015b).
} 
específicas e, um deles, se ocuparia da faculdade da linguagem, um órgão que estaria situado na interface entre o cérebro e a mente.

O modelo de cognição daquela época foi fortemente influenciado pelos pressupostos da Inteligência Artificial. A partir deles, criou-se a ideia de que a cognição humana funcionaria tal qual um computador, ou seja, a mente agiria armazenando informações na memória e manipulando-as simbolicamente.

Apesar do sucesso obtido pelo empreendimento gerativista, percebeu-se, posteriormente, que ele não dava conta de todos os aspectos da cognição. Como apontam Koch e Cunha-Lima (2011), a ideia de que reproduzir o comportamento inteligente equivaleria a compreender como ele acontece nos humanos fracassou e deu lugar a compreensão de que a mente não é modular, uma vez que mantém uma relação de interdependência com o corpo.

Isso significa, em outras palavras, que se tradicionalmente vários ramos das Ciências Cognitivas percebiam a mente como um processador de informações abstrato, diversos estudos passaram a demonstrar que os processos cognitivos estão profundamente enraizados em relação ao corpo físico e sua interação com o mundo (WILSON, 2002).

Inúmeros pesquisadores, das mais diversas áreas, trouxeram suas contribuições para a concretização desse novo pensamento acerca da cognição. No campo da Linguística, mais especificamente, os estudos de George Lakoff e Mark Johnson trouxeram inúmeras evidências da relação estreita entre mente, corpo e linguagem. A obra Metaphors, we live by, publicada em 1980, e traduzida em 2002 para o português com o título de Metáforas da vida cotidiana, é considerada referência no que se refere aos avanços científicos em termos de Linguística Cognitiva.

Foi no final da década de 1990, contudo, que a ideia de mente corporificada, embodied mind, foi amplamente debatida pelos mesmos autores e ganhou ainda mais espaço com a publicação da obra Philosophy in the flesh: the embodied mind and its challenge to Western thought (LAKOFF; JOHNSON, 1999).

O princípio basilar dessa proposta se apoia na premissa de que as experiências corpóreas desempenham papel fundamental no modo como percebemos o mundo a nossa volta. Nosso senso do que é real, se de fato o real existe, segundo os autores, depende crucialmente dos nossos corpos, especialmente do nosso aparato sensório-motor (idem, p. 17).

Atualmente, outro modelo teórico de cognição tem ocupado papel importante nas discussões acerca dos fenômenos linguísticos: a cognição ecológica que, de certo modo, pode ser vista uma extensão da perspectiva corporificada, uma vez que propõe, além da participação do corpo físico, a interação com o segmento ambiental nos processos de significação.

Esse novo paradigma enfatiza que a cognição deve ser concebida em termos de interação entre o organismo e o segmento ambiental. Disto se depreende que participam do processo de produção da linguagem, além de informações de natureza sensório-motora, as informações perceptuais presentes no ambiente que nos cerca. A linguagem, assim,

[...] deixa de ser concebida como um conjunto de símbolos abstratos localizados na cabeça e passa a ser compreendida como uma atividade comportamental modelada pelos acasos da vida, mas que sustenta a unidade do sistema organismo-ambiente em suas interações complexas e dinâmicas (DUQUE, 2015b, p. 75).

Na perspectiva ecológica, a cognição é concebida como sendo estendida, uma vez que considera os elementos do ambiente como extensão do nosso aparato cognitivo, e distribuída, 
por compreender que a cognição não se restringe unicamente ao cérebro, levando em conta a participação de todo o corpo, como um sistema unificado.

Essa relação dinâmica entre organismo-ambiente reflete diretamente, dentre outros aspectos, no modo pelo qual construímos e atribuímos sentido ao mundo e às nossas experiências, ou seja, no processo de categorização, que será discutido a seguir.

\section{Processo de categorização: como atribuímos sentido ao mundo e às experiências?}

A categorização é um mecanismo basilar, uma atividade cognitiva intrínseca à linguagem e, consequentemente, essencial ao modo pelo qual aprendemos a nomear, organizar e compreender o mundo à nossa volta. É graças a esse processo que podemos identificar, diferenciar e classificar desde elementos concretos como, por exemplo, "bola", "carro", "árvore", etc., até elementos extremamente abstratos, como "amor", "solidão", "guerra", dentre outros.

Mas como isso ocorre? $\mathrm{O}$ ato de categorizar seria uma capacidade inata ou uma habilidade adquirida e refinada ao longo da vida, a partir de nossa interação com o mundo? A busca por respostas para elucidar tal questão, que teve início ainda no período da Grécia Antiga e se estende até os dias atuais, deu origem a algumas correntes teóricas que se ocuparam em investigar essa temática.

\section{1 categorização clássica}

As primeiras discussões sobre o modo pelo qual categorizamos o mundo, como dito anteriormente, remontam ao período da Grécia Antiga e já eram abordadas por grandes filósofos, como Platão e Aristóteles. Uma das primeiras teorias que abordaram essa questão, a "Teoria Clássica da Categorização", construiu-se num cenário marcado por embates de pensamentos entre dois grupos de filósofos: os nominalistas e os realistas.

Para explicar o processo de categorização, os nominalistas defendiam que nomeamos as coisas ao nosso redor com base em aspectos puramente convencionais, ou seja, não haveria nenhuma relação entre a palavra e aquilo que foi nomeado. O princípio da arbitrariedade do signo de Saussure, por exemplo, é um clássico representante do pensamento nominalista.

Os realistas, por outro lado, se sustentavam na ideia de que nomeamos os elementos do mundo a partir de características essenciais, uma espécie de substância individual que diferenciaria uma coisa da outra. Nessa perspectiva, as categorias "[...] seriam então preenchidas por elementos que tivessem todos os traços essenciais e, caso não os tivessem, não seriam pertencentes a tal categoria" (SANTOS; MEDEIROS, no prelo). Um exemplo típico da vertente realista são os silogismos aristotélicos.

As duas ideias ora citadas também fizeram parte do raciocínio de Platão. Auroux (2009) nos mostra que, em um dos seus diálogos, o filósofo grego introduz a discussão a respeito da categorização. Em Crátilo: sobre a justeza dos nomes, é possível constatarmos o pensamento nominalista na seguinte fala de Hermógenes:

A meu ver, o nome que se atribui a um objeto é o nome justo; ao muda-lo, em seguida, para outro, abandonando o anterior, o segundo não é menos justo que o primeiro; [...]. Porque a natureza não atribui nome próprio algum a nenhum objeto: isso é uma questão de uso e de costume entre aqueles que desenvolveram o bábito de dar nomes (grifo nosso).

Opondo-se a essa tese, Crátilo acredita que os nomes só podem significar por natureza, ou seja, se dispuserem de alguma propriedade inerente, de uma essência. Esse pensamento, como mencionado anteriormente, se insere na perspectiva realista. 
A abordagem clássica sobre a categorização, cuja principal premissa se fundamenta no pressuposto básico da Teoria dos Conjuntos - pertence ou não pertence - persistiu por cerca de mais de dois mil anos e ainda parece influenciar, de modo geral, a ciência ocidental. Cabe destacar, contudo, que essa teoria, como ressalta Lakoff (1987), não foi resultado de estudos empíricos, mas de uma posição filosófica com base em uma especulação a priori.

Somente a partir do século XX, por intermédio dos avanços científicos no âmbito das Ciências Cognitivas, que novas discussões a respeito do processo de categorização ganharam espaço.

\subsection{Wittgenstein e a categorização por semelhanças de família}

Em 1953, ao propor que as categorias não são elementos estanques, mas, contrariamente, contínuos, o filósofo austríaco Ludwig Wittgenstein chamou a atenção para um novo enfoque a respeito do processo de categorização e, com isso, rompeu com o paradigma essencialista de até então.

Se, no modelo clássico, o elemento decisivo para incluir um membro em uma determinada categoria dizia respeito aos traços essenciais, na perspectiva de Wittgenstein o fator determinante está relacionado às semelhanças de família. A base do seu pensamento, dito de outro modo, é a noção de continuidade.

Para justificar seu raciocínio, o filósofo discute sobre a categoria jogo. Não há, segundo ele, uma substância essencial que a identifique como tal. De acordo com o contexto, "jogo" pode assumir contornos distintos, referindo-se, por exemplo, a um "jogo de futebol", a um "jogo de tênis", assim como a um "jogo de palavras", ou, até mesmo, a expressões idiomáticas do tipo "jogo de cintura".

\subsection{Teoria dos protótipos de Eleanor Rosch}

Outra vertente teórica que abordou o processo de categorização foi desenvolvida na década de 1970, pela pesquisadora e psicóloga Eleanor Rosch. Para essa corrente, categorizamos o mundo de acordo com necessidades específicas.

Em trabalho publicado em 1975, Rosch e Mervis sugerem que categorizamos o mundo a partir de protótipos. As autoras apontam, por exemplo, que como falantes de uma língua, inseridos em uma determinada cultura, nós sabemos que algumas "cadeiras" representam melhor a categoria "mobiliário" do que outras.

Para ilustrar esse raciocínio, podemos pensar no seguinte exemplo: a categoria AVES, para nós, brasileiros, normalmente terá como protótipos espécies como beija-flor, bem-te-vi, arara, entre outras. Por outro lado, para indivíduos que habitam regiões como a do Alasca, a mesma categoria será preenchida, provavelmente, com referentes mais próximos daquela realidade, como os pinguins, por exemplo.

Os trabalhos desenvolvidos por Rosch foram fundamentais e deram sustentação para a construção de uma nova abordagem: a categorização corporificada, discutida a seguir.

\subsection{Categorização corporificada}

Esse novo paradigma de categorização, desenvolvido por Lakoff (1987), é amplamente discutido em Women, fire and dangerous things: what the categories reveal about the mind. O título da obra, segundo o autor, foi inspirado em uma língua de aborígenes australianos, o Dyirbal, que abarca, em uma única categoria (balan), os conceitos de mulher, fogo e coisas perigosas. Isso para mostrar, grosso modo, que além das categorias não serem estanques, também são influenciadas por aspectos culturais. 
Uma das principais características dessa nova proposta diz respeito à compreensão de que o funcionamento da mente está imbricado ao do corpo. O entendimento de que "[...] categorizar significa, antes de tudo, experienciar" (SANTOS; MEDEIROS, no prelo) explica alguns dos diversos mecanismos atrelados à construção da linguagem, dentre os quais se destaca, por exemplo, o modo pelo qual explicamos conceitos abstratos: aproximando-os das nossas experiências corpóreas.

Outro aspecto importante do modelo de categorização corporificada diz respeito à noção de categorias radiais, formulada por Lakoff (1987). Estas, são estruturas que agregam subcategorias em uma categoria mais ampla e se sustentam no princípio básico da radialidade, o de extensão. Isso significa que um modelo central permite que determinada categoria se expanda, como é possível verificarmos no exemplo a seguir:

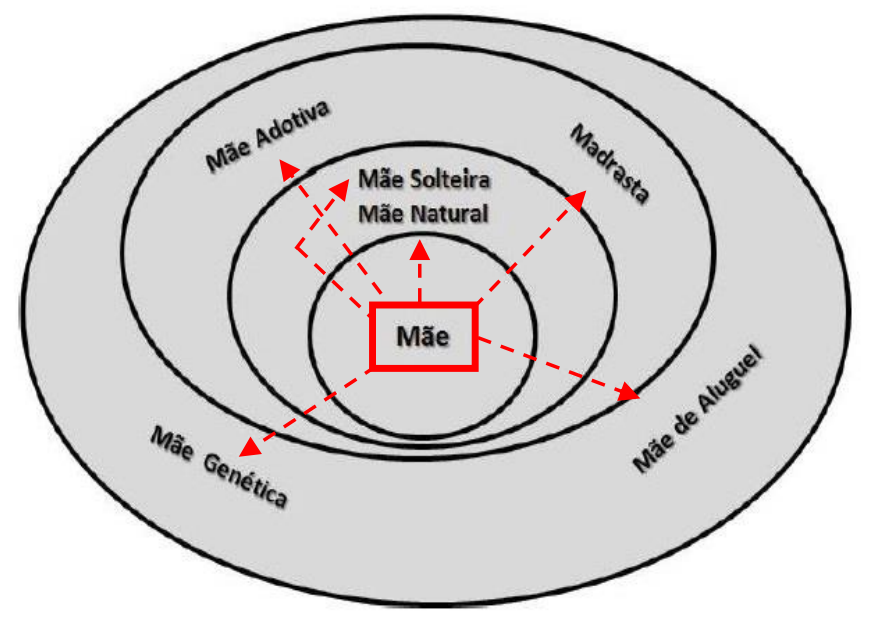

Figura 1. Exemplo de categoria radial (SANTOS; MEDEIROS, no prelo).

A figura 1 mostra que uma categoria prototípica, como é o caso de MÃE, não se fundamenta em traços necessários e suficientes, mas, contrário a isso, apresenta uma estrutura radial que abrange outras categorias, como, MÃE DE ALUGUEL, MÃE ADOTIVA, e assim por diante. É válido destacarmos que uma categoria central, dependendo de fatores como aspectos culturais, por exemplo, pode tornar-se periférica, assim como as categorias menos prototípicas podem assumir o centro da estrutura radial.

A partir da breve síntese apresentada em relação aos estudos desenvolvidos por Wittgenstein, Rosch e Lakoff, é possível percebermos que o processo de categorização não se reduz ao ato de nomearmos objetos e experiências que nos circundam.

Vamos além do "simples" ato de etiquetar as coisas do mundo: somos capazes de conferir sentidos diversos às "etiquetas" que criamos. Isso se deve, principalmente, a capacidade do nosso cérebro (em interação com o ambiente) de conectar informações sensoriais e perceptuais a um mecanismo cognitivo que nos permite criar conceitos sobre as coisas. Esse mecanismo, conhecido por frame, nos parece fundamental para se pensar em uma proposta de categorização a partir do viés ecológico, como será proposto a seguir.

\section{Frames: uma proposta de categorização ecológica}

Os frames são "[...] mecanismos cognitivos através dos quais organizamos pensamentos, ideias e visões de mundo" (DUQUE, 2015a). Dito de outro modo, podemos pensar em frames como sendo um conjunto de experiências armazenado em nossa memória de longo prazo, a 
respeito de um determinado conceito, cujo sentido vai sendo gradativamente construído. É por essa razão que, segundo Lakoff (2004), quando ouvimos uma palavra, o frame a ela relacionado, ou uma coleção de frames, é ativado em nosso cérebro.

Conforme Duque (2015a), o frame apresenta uma estrutura reticulada, o que significa que quando pensamos sobre determinado conceito, não o pensamos de modo isolado, mas, contrariamente, ativamos em nosso cérebro todas as nossas experiências a ele relacionadas. Essa visão se fundamenta nos princípios da Teoria Neural da Linguagem, segundo a qual o frame pode ser pensado como "[...] uma 'cascata' de circuitos neurais acionada por palavras" (LAKOFF; WEHLING, 2012, apud DUQUE, 2015a).

Ao pensarmos, lermos ou ouvirmos algo como "futebol", por exemplo, ativamos em nosso cérebro uma rede de informações que envolve, além do nosso conhecimento de mundo sobre o tema, como time, juiz, bola, chuteiras, uniformes, entre outros, experiências individuais, como o fato de preferir o time $\mathrm{X}$ a $\mathrm{Y}$, de ter presenciado determinado jogo, em determinado lugar, etc.

Os frames podem ser universais, esquemas- $\mathrm{I}^{5}$ e esquemas- $\mathrm{X}^{6}$, e/ou culturais, cujas especificidades são definidas culturalmente. $O$ caráter universal diz respeito às experiências de natureza sensório-motora, resultantes das relações entre nossas limitações corpóreas e o ambiente. O caráter cultural, como o próprio conceito sugere, emerge em cenários de experiências socioculturais específicos. Nesse sentido, o frame CASAMENTO, por exemplo, evocará aspectos distintos, de acordo com cada cultura.

O conceito que tenho de ÁRVORE, por exemplo, foi construído ao longo de tudo aquilo que experimentei em relação a ela ao longo da vida. Isso compreende, dentre outras coisas, lembranças como as de quando eu subia nas árvores do quintal de casa para comer seus frutos. Esse conceito, que é pessoal, não será o mesmo para outras pessoas, visto que será preenchido por experiências distintas das minhas.

O que pretendemos tornar perceptível é que o nosso conceito sobre ÁRVORE, construído com base em uma gama particular de experiências, não pode ser reduzido, por exemplo, a uma das definições encontradas em um dicionário de língua portuguesa:

\section{s.f. Planta lenhosa cujo caule, ou tronco, fixado no solo com raízes, é despido na base e carregado de galhos e folhas na parte superior.}

Figura 2. Definição da palavra “árvore”. Fonte: http://www.dicio.com.br/arvore/

Nesse sentido, é necessário esclarecermos a distinção entre definição e conceito. Enquanto a primeira diz respeito a um significado estanque, a uma mera representação, o segundo se refere ao conjunto de experiências de um sujeito em relação às coisas ou às situações e, por essa razão, não é único.

Em outras palavras, a noção de conceito se conecta a uma estreita relação entre as informações perceptuais oriundas do segmento ambiental, o entorno cultural e as experiências intersubjetivas de cada um. É a partir disso que somos capazes de categorizar novos elementos, criando novos conceitos, ou de recategorizar aqueles já existentes, alimentando-os com novas informações.

\footnotetext{
${ }^{5}$ Padrões cognitivos formados com base em informações sensoriais.

${ }^{6}$ Padrões cognitivos construídos a partir de reações motoras.
} 
Evans e Green (2006) assinalam que um conceito é construído a partir de perceptos, isto é, daquilo que nosso cérebro é capaz de captar em relação aos elementos disponíveis no ambiente. Essas informações são conectadas em uma imagem mental ${ }^{7}$, que por sua vez dá origem a um determinado conceito.

Além das informações perceptuais fornecidas pelo ambiente, cabe relembrarmos, devem ser considerados determinantes, no processo de construção de conceitos, as experiências individuais do sujeito e o contexto cultural no qual estão inseridos.

Diante do exposto e na tentativa de tornar claro o que foi dito, poderíamos ilustrar o modo pelo qual os conceitos são cognitivamente construídos através do seguinte exemplo:

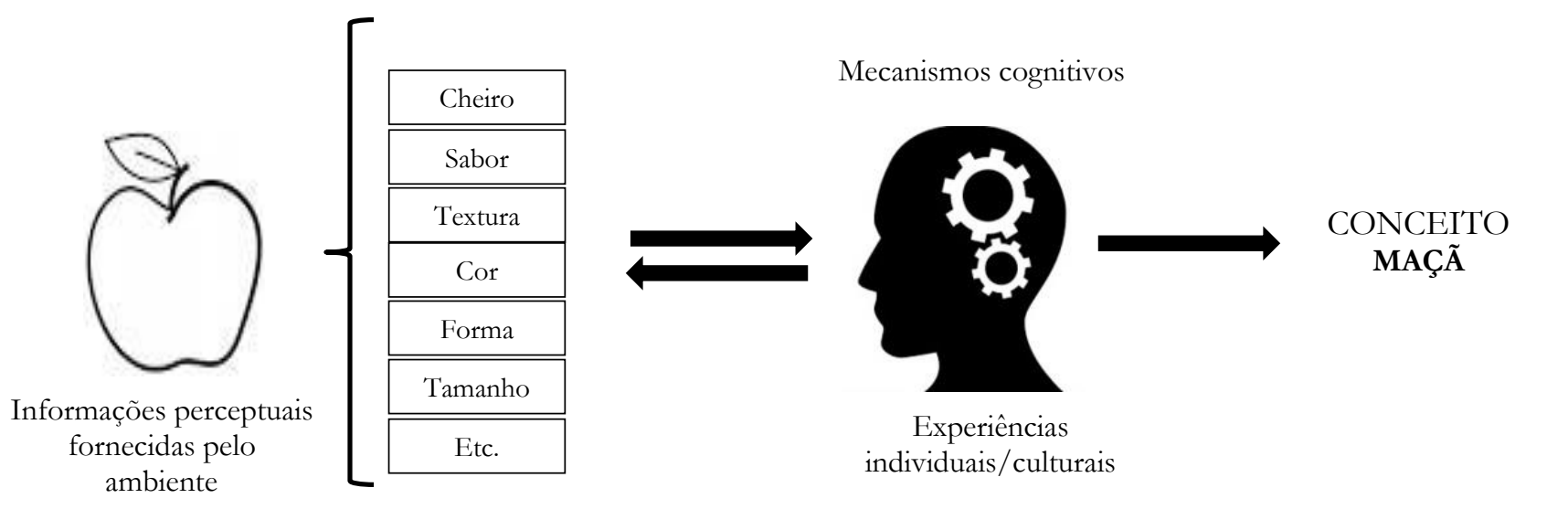

Figura 3. Processo cognitivo de construção de conceitos.

É válido destacarmos que o "conteúdo" dos conceitos não é estanque, como no caso das definições encontradas em dicionários. Se, por um lado, as informações perceptuais fornecidas pelo segmento ambiental são, em certa medida, estáveis, a maneira pela qual elas são gerenciados por nosso aparato cognitivo é extremamente dinâmica, uma vez que envolve, além de experiências subjetivas, aspectos de natureza cultural, como mencionado anteriormente.

Isso significa, em outras palavras, que um conceito como MAÇÃ, como visto na ilustração anterior, além de não ser único, pode ser modificado na medida em que, a partir de cada nova experiência vivenciada, sejam acrescentadas novas informações ou retiradas algumas já existentes.

Os elementos que preenchem os conceitos, as informações perceptuais decorrentes do segmento ambiental e as experiências subjetivas e culturais de cada sujeito, vão se agrupando em espécies de molduras nos nossos cérebros. Essas molduras, que carregam todas essas informações a respeito de alguma coisa ou de determinada situação, correspondem aos frames.

Eles desempenham papel crucial no modo pelo qual percebemos o mundo a nossa volta, seja criando novos conceitos ou reconfigurando os já existentes. É por essa razão que, partindo da ideia de que os frames nos auxiliam a categorizar e a recategorizar o ambiente que nos cerca,

7 “[...] uma representação disponível da consciência” (idem, p. 4). 
acreditamos ser possível pensar em um modelo de categorização a partir da perspectiva ecológica $^{8}$ e da noção de frames.

Ao sugerir esse possível paradigma pretendemos ratificar a ideia de que os sentidos não repousam sobre as palavras e de que os conceitos não são meras definições pré-estabelecidas em nossas mentes, como propõem as abordagens de natureza representacionista. A esse respeito, Duque (2015b, p. 61) nos lembra que

qualquer teoria que separe o agente do ambiente e o agente de outros agentes está fadada a lidar, não com conceitos, mas com definições destituídas de qualquer sopro de vida, pois um conceito só pode ser apreendido e aprendido e compreendido nas relações intersubjetivas que pavimentam nossos nichos ecológicos.

Conceitos são (re)criados dinamicamente e o conjunto de informações que a eles se relaciona, os frames, são decorrentes da estreita relação entre ambiente, cognição e linguagem.

\section{CONSIDERAÇÕES FINAIS}

Ao longo deste texto, buscamos traçar um breve panorama a respeito das duas grandes vertentes da linguística cognitiva: o modelo clássico, de base modular, e o modelo ecológico, perspectiva mais recente que pode ser considerada extensão do paradigma corporificado.

Para tanto, elencamos dois conceitos que julgamos fundamentais a qualquer discussão acerca das relações existentes entre mente e linguagem: cognição e categorização, abordando-os a partir das abordagens acima mencionadas.

O maior objetivo deste trabalho, além de apresentar, mesmo que de modo breve, as características epistemológicas da cognição e da categorização, foi o de sugerir, a partir de indícios que apontam para o importante papel que desempenha o ambiente no processo de construção de conceitos, ser possível pensar em um novo paradigma de categorização, estando este situado na perspectiva ecológica da linguagem. Propusemos, também, alguns exemplos para tornar clara a diferença entre definição e conceitos.

Nessa possível proposta de categorização ecológica, os frames, compreendidos como o conjunto de informações perceptuais, experiências individuais e aspectos culturais, que preenche determinado conceito, são vistos como um mecanismo cognitivo fundamental ao modo pelo qual categorizamos o mundo.

\section{REFERÊNCIAS}

AUROUX, S. Filosofia da linguagem. Tradução de Marcos Marcionilo. São Paulo: Parábola, 2009.

CHOMSKY, N. Syntactic structures. The Hague: Mouton, 1957.

DUQUE, P. H. Discurso e cognição: uma abordagem baseada em frames. Anpoll. v. 1, n. 39, $2015 \mathrm{a}$.

\footnotetext{
${ }^{8}$ Cumpre ressaltarmos que o termo "categorização ecológica" não é novo e já era abordado na década de 1980 a partir de trabalhos como, por exemplo, o de Bideaud (1989). O que propomos, neste artigo, é pensar em um modelo ecológico a partir da concepção de frames utilizada, principalmente, por Duque (2015a).
} 
2015b.

Por uma abordagem ecológica da linguagem. Pontos de Interrogação, v. 5, n. 1, jan./jul.

EVANS, V.; GREEN, M. What does it mean to know a language? In: Cognitive Linguistics: an introduction. Edinburgh: Edinburgh University Press, 2006. p. 5-26.

KOCH, I. V.; CUNHA-LIMA, M. L. Do cognitivismo ao sociocognitivismo. In: MUSSALIM, F.; BENTES, A. C. (Orgs.). Introdução à linguistica: fundamentos epistemológicos. 5.ed. São Paulo: Cortez, 2011. p. 251-300.

LAKOFF, G. Women, Fire and Dangerous Things: what categories reveal about the mind. University of Chicago Press, 1987.

Don't think of an elephant!: know your values and frame the debate: the essential guide for progressives. Berkeley, Chelsea Green: 2004.

LAKOFF, G.; JOHNSON, M. L. Metáforas da vida cotidiana. Tradução de Mara Zanotto. Campinas: Mercado das Letras, 1980 [2002].

Books, 1999.

Philosophy in the flesh: the embodied mind and its challenge to Western thought. New York: Basic

ROSCH, E.; MERVIS, C. B. Family resemblances: studies in the internal structure of categories. Cognitive Psychology, 7, 573-605, 1975.

SANTOS, R. Y.; MEDEIROS, I. S. de. A categorização como processo de construção do mundo: O que a teoria neural tem a contribuir para os estudos da cognição e da linguagem. No prelo.

WILSON, M. Six views of embodied cognition. Psychonomic Bulletin \& Review, 2002, 9 (4), 625-636.

WITTGENSTEIN, L. J. J. Investigações Filosóficas. Tradução de José Carlos Bruni. São Paulo: Nova Cultural, 1953 [1991].

Recebido em 10/02/2017

Aceito em 22/03/2017

Publicado em 14/08/2017 